\title{
Temporal and spatial changes of water quality and management strategies of Dianchi Lake in southwest China
}

\author{
T. Zhang ${ }^{1}$, W. H. Zeng ${ }^{1}$, S. R. Wang ${ }^{2}$, and Z. K. Ni ${ }^{2}$ \\ ${ }^{1}$ State Key Laboratory of Water Environment Simulation, School of Environment, Beijing Normal University, Beijing, China \\ ${ }^{2}$ Research Center of Lake Environment, Chinese Research Academy of Environment Sciences, Beijing, China
}

Correspondence to: W. H. Zeng (zengwh@bnu.edu.cn)

Received: 4 December 2013 - Published in Hydrol. Earth Syst. Sci. Discuss.: 17 December 2013

Revised: 4 March 2014 - Accepted: 5 March 2014 - Published: 23 April 2014

\begin{abstract}
Temporal and spatial changes to the water quality of Dianchi Lake in southwest China were investigated using monthly monitoring data from 2005 to 2012. Dianchi Lake is divided into two parts, Caohai Lake and Waihai Lake, by a man-made dike. Caohai Lake lies at the north of Dianchi Lake, while Waihai Lake is the main water body of Dianchi Lake and accounts for $96.7 \%$ of the whole area of the lake. Based on the analysis of total phosphorus (TP), total nitrogen (TN), and chlorophyll $a(\mathrm{Chl} a$ ) concentrations, it was determined that, in Caohai Lake, the annual concentrations of these variables ranged from $0.19-1.46 \mathrm{mg} \mathrm{L}^{-1}$, $6.11-16.79 \mathrm{mg} \mathrm{L}^{-1}, 0.06-0.14 \mathrm{mg} \mathrm{L}^{-1}$, respectively. In addition, the annual concentrations of TP, TN and Chl $a$ in Waihai Lake ranged between 0.13 and $0.20 \mathrm{mg} \mathrm{L}^{-1}, 1.82$ and $3.01 \mathrm{mg} \mathrm{L}^{-1}$, and 0.04 and $0.09 \mathrm{mg} \mathrm{L}^{-1}$, respectively. Cluster analysis (CA) classified the 10 monitoring sites into two clusters (cluster A and cluster B) based on similarities of water quality characteristics. Our data revealed that the current status of water quality within Caohai Lake was much worse than that of Waihai Lake. Water quality was seriously degraded during the economic boom near the period of the "Eleventh Five-Year Plan" (2005-2010), and gradually improved from 2010 to 2012 because of the "standard emission directive to industry". The main factors that influenced the spatial and temporal changes to water quality were natural factors including lake evolution and regional characteristic as well as human factors such as pollution load into the lake and management strategies that were already adopted. Some activities and regulations were implemented to enhance the lake environment by controlling wastewater emissions and establishing regulations to protect the lakes in the Yunnan Province. However, problems with institutional
\end{abstract}

fragmentation (horizontal and vertical), simple treatment methods, low-intensity investment in pollution control, and lack of meaningful endogenous pollution control strategies were still present in the lake management strategy. To solve these problems, suitable control measures are needed, especially considering the current old-age status of Dianchi Lake. The fundamental improvement of the water quality within Caohai Lake was dependent on the measures taken in the upper reaches of the Caohai Watershed, including further recovery of submerged plants, resource utilization by floating plants and the reinforcement of sediment disposal. Management strategies for endogenous pollution in Waihai Lake were mainly dependent on restocking algae-eating fish and the ecological restoration of macrophytes. In this way, the swamping trend and the ageing process that is occurring in Dianchi Lake can be stunted. And the management strategies would be a contribution to the management of water conflicts between mankind and ecosystems in similar lakes.

\section{Introduction}

The formation, development, and evolution of lakes have recorded regional environmental changes because they are relatively independent, natural complexes. Due to historical rapid population growth and development of industry and agriculture in the lake catchment region, the lake has become shallower as it has aged and will eventually fill up (Wang and Dou, 1999). The lifetime of a lake ranges from thousands of years to millions of years, and can be divided into several stages: adolescence, adulthood, old age, and decline (adolescence - Lugu Lake, adulthood - Taihu Lake, old age - 
Dianchi Lake, and the decline phase - Lop Lake). For example, at the beginning of the formation of a rift lake, which forms due to large-scale fault activity, the subsidence of the lake basin changes rapidly and the basin is mainly filled with accumulated coarse sediments. As the lake reaches adulthood, the subsidence gradually slows down and a lacustrine delta develops. At this point, the lake changes from deep to shallow and the main sediments become fine grained. In addition, aquatic plants and phytoplankton increase to large numbers. Throughout the old age phase, a large amount of sediment fills up the lake basin due to greater sedimentation causing the water area to become narrow and shallow until, finally, a swamp lake evolves (Wang and Dou, 1999). Furthermore, water quality changes in eutrophication go from moderate (adolescence) to slightly eutrophicate (adulthood) and finally to a midrange of eutrophication (old age). This is the process of lake evolution from young age to old age (Yang et al., 2010). Lastly, Lop Lake presents a good example of changes to water flow and water area, whereby the overall trend is that lakes shrink and even dry up to disappear as they evolve to later stages. Under natural conditions, the lake aging process develops slowly; however, with the development of social economy in many areas, the evolution and disappearance of lakes have been greatly accelerated (Katsuki et al., 2009; Choudhary et al., 2010; Kabir et al., 2011; Zan et al., 2012). Similar to aging people, in the process of lake development, when a lake becomes old, it will attempt to maintain its previous level of function but never has exactly the same biological and chemical components and concentrations. Therefore, for each evolution stage in different lakes, we should adhere to specific management strategies to keep the lake in a healthy state (Laghari et al., 2012).

Dianchi Lake is a typical lake that was formed in approximately $3000 \mathrm{ka} \mathrm{BP}$ in the late Pliocene. After a long-term evolution, Dianchi Lake is now becoming an overcompensation lake in the late stage of its evolution (Yu et al., 1990). By analyzing various environmental parameters recorded in the lake sediments, including pollen, TOC, TN, and many other indicators of susceptibility, the evolutionary history of Dianchi Lake has been reconstructed from approximately $13 \mathrm{ka}$ BP. It was reported that during the Han and Tang Dynasties, the lake level was approximately $3 \mathrm{~m}$ lower than today. Between the 1960s and the 1970s, rapid economic development coupled with reclamation, soil erosion, and siltation, caused the water quality of Dianchi Lake to seriously deteriorate (Wu et al., 1998). Over the last 50 years, the water quality in Dianchi Lake has been degrading rapidly and, as a result eutrophication has become the most pervasive threat to the lake (Tuo, 2002; Xing et al., 2005; Zhang et al., 2009; Le et al., 2010; Li et al., 2012). Although much work has been done to control the water quality, the eutrophication problem has not yet been solved. Therefore, it has become a primary problem that is restricting the economic development of Kunming

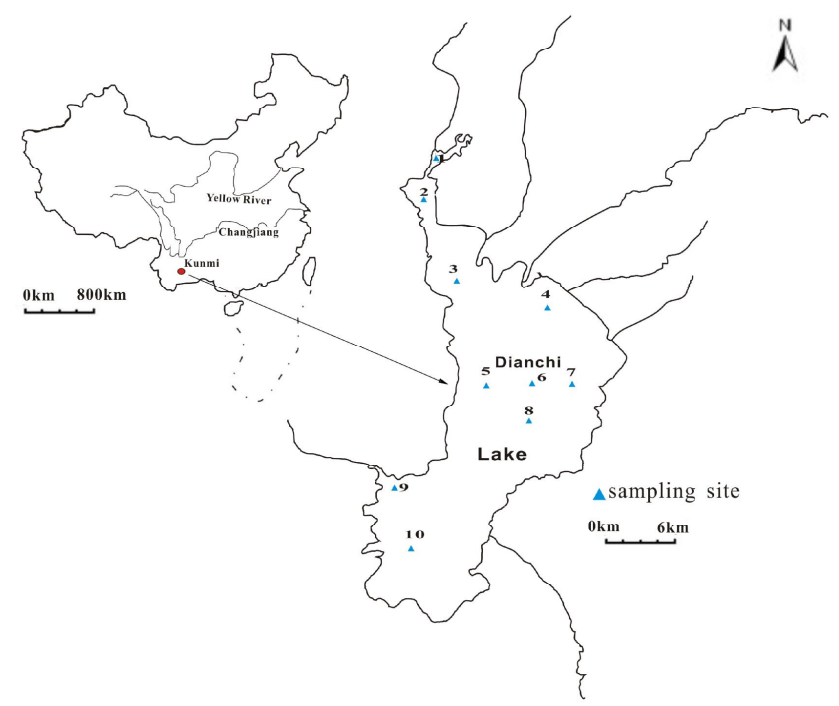

Fig. 1. A map showing the location of the study area and the sampling sites.

City. In addition, the lack of water as a resource is another long-term issue to which we should pay close attention.

Although many researchers have already made some achievements with Dianchi Lake, most of the previous studies have focused only on lake surface water quality (Yang et al., 2010) or on the water quality among the rivers (Yu et al., 2010; Huan et al., 2010). The implemented control strategies are fragmented, and these strategies have ignored that this lake is in an old evolution stage. The objective of this study was to investigate the temporal and spatial changes to the water quality of Dianchi Lake and determine Dianchi Lake's primary problems. In addition, the current status of the old-age lake will be considered, and some management strategies tailored to the evolution course of Dianchi Lake will be given. The results of this study will be useful to the policy makers around the country and abroad that are making decisions regarding control of environmental problems in Dianchi Lake or other similar lakes. Moreover, the results could contribute to the management of water conflicts between mankind and ecosystems (Christofides et al., 2005; Cai et al., 2009).

\section{Material and methods}

\subsection{Study area and monitoring sites}

Dianchi Lake $\left(24^{\circ} 40^{\prime}-25^{\circ} 02^{\prime} \mathrm{N}, 102^{\circ} 36^{\prime}-102^{\circ} 47^{\prime} \mathrm{E}\right)$ is a rift lake that is located in Kunming City in the Yunnan Province of southwest China (Fig. 1). Its average water depth is approximately $5 \mathrm{~m}$, its maximum water depth is $8 \mathrm{~m}$, and its surface area is approximately $306 \mathrm{~km}^{2}$ (Du et al., 2011). Dianchi Lake is divided into two parts, Caohai Lake and Waihai Lake, by a man-made dike. Caohai Lake lies at the north of 
Table 1. Correlation coefficients between the environmental variables in Dianchi Lake (Pearson, two-tailed).

\begin{tabular}{|c|c|c|c|c|c|c|c|c|c|c|}
\hline Variables & Chl $a$ & $\begin{array}{r}\text { Water } \\
\text { temperature }\end{array}$ & $\mathrm{PH}$ & DO & $\mathrm{COD}_{\mathrm{Mn}}$ & COD & $\mathrm{BOD}_{5}$ & $\mathrm{NH}_{4}{ }^{+}-\mathrm{N}$ & $\mathrm{TP}$ & $\mathrm{TN}$ \\
\hline Chl $a$ & 1 & & & & & & & & & \\
\hline $\begin{array}{l}\text { Water } \\
\text { temperature }\end{array}$ & .093 & 1 & & & & & & & & \\
\hline $\mathrm{PH}$ & $-.250^{*}$ & .019 & 1 & & & & & & & \\
\hline DO & $-.408^{* *}$ & .074 & $.645^{* *}$ & 1 & & & & & & \\
\hline $\mathrm{COD}_{\mathrm{Mn}}$ & $.317^{* *}$ & $-.244^{*}$ & $.249^{*}$ & -.108 & 1 & & & & & \\
\hline COD & -.165 & $.270^{*}$ & $.451^{* *}$ & $.410^{* *}$ & .09 & 1 & & & & \\
\hline $\mathrm{BOD}_{5}$ & $.563^{* *}$ & .058 & $-.731^{* *}$ & $-.753^{* *}$ & -.075 & $-.624^{* *}$ & 1 & & & \\
\hline $\mathrm{NH}_{4}^{+}-\mathrm{N}$ & $.352^{* *}$ & .123 & $-.695^{* *}$ & $-.792^{* *}$ & -.042 & $-.424^{* *}$ & $.819^{* *}$ & 1 & & \\
\hline $\mathrm{TP}^{4}$ & $.418^{* *}$ & .169 & $-.658^{* *}$ & $-.745^{* *}$ & -.045 & $-.365^{* *}$ & $.787^{* *}$ & $.968^{* *}$ & 1 & \\
\hline $\mathrm{TN}$ & $.410^{* *}$ & .061 & $-.762^{* *}$ & $-.823^{* *}$ & -.036 & $-.494^{* *}$ & $.878^{* *}$ & $.983^{* *}$ & $.947^{* *}$ & 1 \\
\hline
\end{tabular}

* Correlation is significant at the 0.05 level (two-tailed). ** Correlation is significant at the 0.01 level (two-tailed).

Dianchi Lake, while Waihai Lake is the main water body of Dianchi Lake and accounts for $96.7 \%$ of the whole area of the lake.

Previous paleoenvironmental studies have shown that based on the long-term evolution of Dianchi Lake, it has been classified as an old-age lake (Yu et al., 1990). In addition, the ecological environment in Dianchi Lake has seriously deteriorated since the 1960s because of rapid economic development and its associated human activities, such as cultivation and fishing (Gao et al., 2004; Cai et al., 2011; Wang et al., 2009; Guo et al., 2013).

We have analyzed the water quality parameters in order to investigate the temporal and spatial changes of water quality in Dianchi Lake. Data for lake water quality from 2005 to 2012 were provided by the Center for Environmental Monitoring in Kunming, Yunnan Province. Twelve water quality parameters, including dissolved oxygen (DO), permanganate index $\left(\mathrm{COD}_{\mathrm{Mn}}\right)$, biological oxygen demand $\left(\mathrm{BOD}_{5}\right)$, ammonia $\left(\mathrm{NH}_{4}{ }^{+}-\mathrm{N}\right)$, chemical oxygen demand (COD), total phosphorus (TP), total nitrogen (TN), and chlorophyll $a$ (Chl $a$ ) were collected monthly from the monitoring stations.

The sampling points are shown in Fig. 1. Ten water quality sampling points were established for monitoring water quality in Dianchi Lake. Of these points, two were in Caohai Lake (points 1 and 2) and the other eight were in Waihai Lake. The names of each of the sampling points from 1 to 10 were Duanqiao (DQ), the center of Caohai $(\mathrm{CH})$, Luojiaying (LJY), middle of Huiwan (HW), Guanyinshan West (GYSW), middle of Guanyinshan (GYSM), Guanyinshan East (GYSE), Baiyukou (BYK), Haikou West (HKX) and Dianchi South (DCS). The sampling depth at each point was $0.5 \mathrm{~m}$ below the water surface, and the monitoring frequency was once a month. The sampling, preservation, transportation, and analysis of the water samples were performed following standard methods (State Environment Protection Bureau of China, 2002).

\subsection{Study methodology}

\subsubsection{Independent $t$ test and Pearson correlation}

Statistical analysis was conducted using the SPSS 20.0 software package. One-way analysis of variance (ANOVA) (LSD test) and independent-sample $t$ tests at the 0.05 confidence level were conducted to test the difference between group mean values. A two-tailed Pearson correlation analysis was conducted to illustrate the correlative relationships between water parameters.

\subsubsection{Cluster analysis}

CA is an unsupervised pattern detection method that partitions all dissimilar cases into different groups (Shrestha and Kazama, 2007; Lu et al., 2011; Gbolo and Gerla, 2013). The results of CA help to interpret the data and indicate patterns (Singh et al., 2004). Hierarchical CA, the most common approach, starts with each case in a separate cluster and joins the clusters together step by step until only one cluster remains (Lattin et al., 2003; McKenna, 2003). In this study, hierarchical CA was performed on the standardized data using Ward's method with squared Euclidean distances as a measure of similarity (Zhou et al., 2007). Ward's method uses analysis of variance (ANOVA) to calculate the distances between clusters to minimize the sum of squares of any two possible clusters at each step, and it was expressed as follows:

$d_{i j}=\left[\sum_{k=1}^{m}\left(x_{i k}-x_{j k}\right)^{2}\right]^{\frac{1}{2}} \quad(i, j=1,2 \ldots n)$,

where $d_{i j}$ is the distance between the $i$ th sample and the $j$ th sample, $x_{i k}$ is the $k$ th parameter of the $i$ th sample, $x_{j k}$ is the $k$ th parameter of the $j$ th sample, and $i, j=1,2,3, \ldots, 10$. 

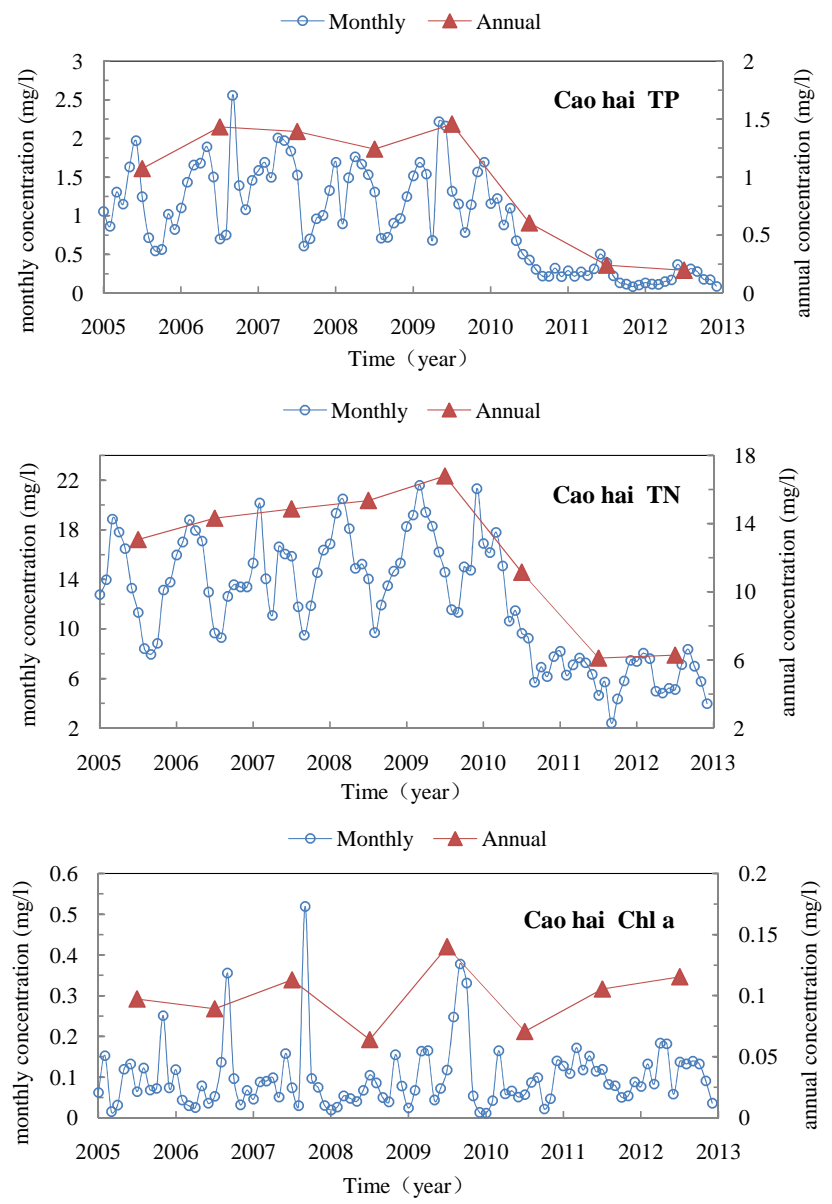

Fig. 2. Temporal changes of TP, TN, and Chl $a$ in Caohai Lake.

\section{Results}

\subsection{Temporal changes of TP, TN and Chl $a$ in Dianchi Lake}

Temporal changes in TN, TP, and Chl $a$ are shown in Figs. 2 and 3 and were based on the monitoring data collected at ten sites in Dianchi Lake from 2005 to 2012.

Monthly concentrations of TP, TN and Chl $a$ in Caohai Lake ranged from $0.08 \mathrm{mgL}^{-1}$ (November 2011) to $2.56 \mathrm{mg} \mathrm{L}^{-1}$ (September 2006), $2.42 \mathrm{mg} \mathrm{L}^{-1}$ (September 2011) to $21.6 \mathrm{mg} \mathrm{L}^{-1}$ (March 2009), and $0.01 \mathrm{mg} \mathrm{L}^{-1}$ (January 2010) to $0.52 \mathrm{mg} \mathrm{L}^{-1}$ (September 2007), respectively. The annual concentrations of TP, TN and Chl $a$ in Caohai Lake were from 0.19 to $1.46 \mathrm{mg} \mathrm{L}^{-1}, 6.11$ to $16.79 \mathrm{mg} \mathrm{L}^{-1}$, and 0.06 to $0.14 \mathrm{mg} \mathrm{L}^{-1}$, respectively. The monthly concentrations of TP and TN declined gradually; however, no obvious trend was found for Chl $a$ concentrations.

Monthly concentrations of TP, TN and Chl a in Waihai Lake ranged from $0.06 \mathrm{mg} \mathrm{L}^{-1}$ (October 2007) to $0.36 \mathrm{mg} \mathrm{L}^{-1}$ (September 2006), $1.06 \mathrm{mg} \mathrm{L}^{-1}$
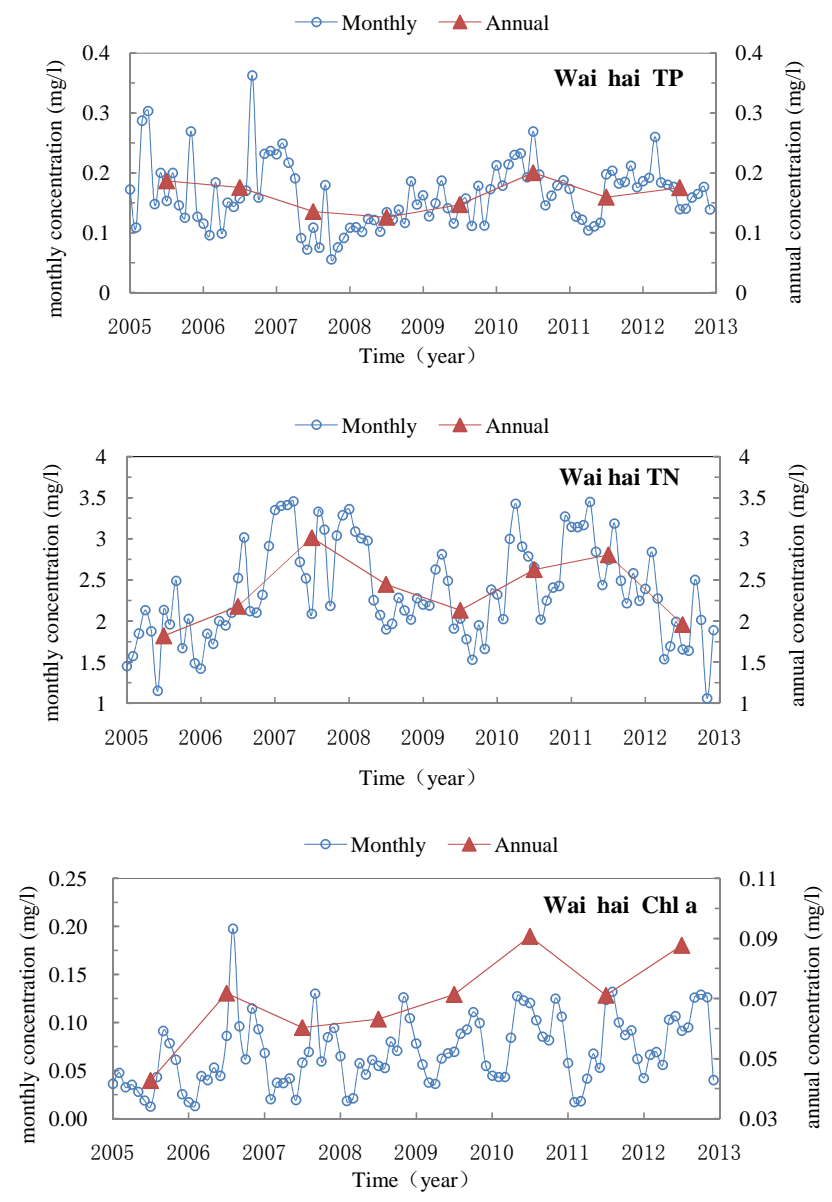

Fig. 3. Temporal changes of TP, TN, and Chl $a$ in Waihai Lake.

(November 2012) to $3.46 \mathrm{mg} \mathrm{L}^{-1}$ (April 2011), and $0.01 \mathrm{mg} \mathrm{L}^{-1}$ (February 2006) to $0.20 \mathrm{mg} \mathrm{L}^{-1}$ (August 2006), respectively. In addition, the annual concentrations of TP, TN and Chl $a$ in Waihai Lake ranged from 0.13 to $0.20 \mathrm{mg} \mathrm{L}^{-1}$, 1.82 to $3.01 \mathrm{mg} \mathrm{L}^{-1}$, and 0.04 to $0.09 \mathrm{mg} \mathrm{L}^{-1}$, respectively. No clear temporal trends for these three water parameters were observed.

The correlative relationships between environmental variables were analyzed. The results showed that $\mathrm{Chl} a$ had a significant positive correlation to $\mathrm{BOD}_{5}$, TP, and TN. In addition, TN and TP were both negatively correlated to $\mathrm{PH}$, $\mathrm{DO}, \mathrm{COD}_{M n}$, and COD (Table 1), a finding that has been reported in other lakes (Yang et al., 2013).

Eutrophication is the most widespread water quality problem in many countries, especially China (Xia et al., 2011; Liu et al., 2012; Wang et al., 2012). Our results showed that the annual concentrations of TP, TN, and Chl $a$ in Caohai Lake were significantly higher than those in Waihai Lake, which indicated that the current status of water quality of Caohai Lake is much worse than that of Waihai Lake. According to the classification of water parameters outlined in the Environmental Quality Standards for Surface Water, which has 


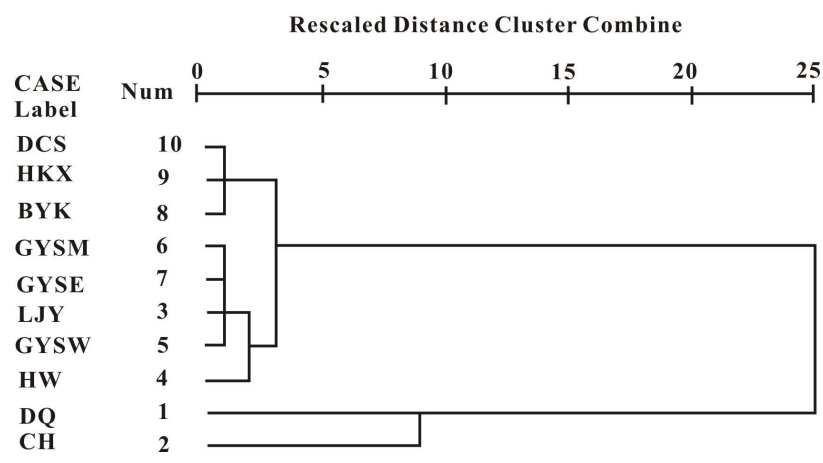

Fig. 4. Dendrogram showing sampling site clusters on Dianchi Lake.

been promoted by the Chinese government, the water quality of Caohai Lake was in a heavy eutrophic state during this study period and was categorized below Class V. Similarly, water quality in Waihai Lake was also below Class V and the eutrophic state was moderate. As the water quality continues to deteriorate, the trophic condition of Dianchi Lake will become more and more serious.

In this study, changes were observed in the water quality of the whole lake from 2005 to 2012 based on three major indicators: TP, TN, and Chl $a$. The water quality in the lake experienced two stages: (1) 2005-2010, when water quality was seriously degraded during the economic boom during the period of the "Eleventh Five-Year Plan" and (2) 2010-2012, when water quality gradually improved because of the "standard emission directive to industry". A series of environmental problems arose during the first stage due to a lack of environmental consciousness by managers at different government levels (Wang and Lin, 2010; Veld and Shogren, 2012). Three indicators reached their maximum during this period: TP in 2006 with a value of $2.56 \mathrm{mg} \mathrm{L}^{-1}$, TN in 2009 with a value of $21.6 \mathrm{mg} \mathrm{L}^{-1}$, and Chl $a$ in 2007 with a value of $0.52 \mathrm{mg} \mathrm{L}^{-1}$. In the second stage, from 2010 to 2012, the indicator values declined, especially in Caohai Lake. The improvement was related to the Chinese government and the Yunnan Province placing great importance on the management of the Dianchi Lake watershed.

\subsection{Spatial changes of TP, TN and Chl $a$ in Dianchi Lake}

Spatial CA produced a dendrogram with two groups (Fig. 4). Cluster A comprised sites 1-2, and cluster B contained sites 3-10. Cluster B was further divided into two groups: sites $8-10$ in group B and the other sites (3-7) in group C. All classifications had varied significance levels because the sites within the groups had similar natural backgrounds and were likely affected by similar pollution sources. Sites 1-2 in cluster A were located in Caohai Lake and were primarily impacted by industrial wastewater, agricultural runoff, and municipal sewage, which corresponded to areas with relatively high pollution. The other sites in cluster B were located in Waihai Lake, with sites 3-7 located in the northern part of Waihai Lake and sites 8-10 located in the southern part of the lake. Clusters A (sites 1-2) and B (sites 3-10) corresponded to relatively high and low polluted regions, respectively. These results suggest that pollution control treatments should be assessed in each region.

\section{Discussion}

\subsection{Influence factor analysis for spatial and temporal distribution of water quality}

\subsubsection{Natural factors}

Dianchi Lake is a typical plateau lake in China. The tributaries that flow into the lake outnumber those that go out of the lake and water resources are scarce. As a result, the water renewal period is much longer. In this case, inputs of salts and other substances could easily accumulate in the lake (Wang and Dou, 1999). During the long-term evolution of Dianchi Lake, factors such as fragile ecological conditions, a shallow water level, insufficient inflow, and the age stage of the lake have caused the pollution in the lake to be more serious and the water quality to become increasingly deteriorated (Cai et al., 2007; Tan et al., 2009). The spatial distribution of water quality is related to the regional characteristics and development of the Dianchi basin; different areas were not the same as others, so the changes in water quality appeared to have different tendencies. The spatial changes in water quality showed that Caohai Lake was seriously polluted because Caohai Lake was the only water body that received domestic sewage and wastewater from treatment plants in the western part of the main urban area.

\subsubsection{Human factors}

The main sources of pollution in Dianchi Lake were the large population and the irrational exploitation of resources. Industrial pollution, agriculture pollution, and other domestic pollution, which directly threatened the water quality of Dianchi Lake, were the primary causes of water eutrophication in Dianchi Lake. There were also many agricultural lands and farms around the lake, which produced large amounts of agricultural non-point source pollution. This run-off could not be effectively controlled and thereby contributed to high levels of pollution.

Flowers and plants are the local specialty of the Yunnan Province. Due to the large planting area and high fertilizer usage, undegraded and unabsorbed fertilizer was washed into the water (Gao and Yang, 2006). However, abundant rock phosphate was found around Waihai Lake. Because of the unreasonable mining and wanton destruction of surface vegetation, a large amount of phosphorus entered Waihai Lake 
and gradually accumulated during the evolution of the lake, eventually becoming a substantial threat to the water quality (Tanaka et al., 2013).

In addition, endogenous pollution is a factor that should not be ignored. Due to the long period of eutrophication, Dianchi Lake is covered with a thick layer of sediment, which contains humus and organic matter and could become another source of pollution to the water column (Tan et al., 2010).

According to research, $187446 \mathrm{t}$ of phosphorus was contained in $0.3 \mathrm{~m}$ of sediment, an amount that was 500 times greater than the phosphorus contained in the water column (Guo, 2003). Therefore, when the concentration of nitrogen and phosphorus in the water decreases, the nitrogen and phosphorus in the sediments will spontaneously release and become another major source of pollution.

Additionally, the temporal distribution of water quality in Caohai Lake and Waihai Lake showed that the year-to-year differences in water quality were also related to the control strategies that were adopted. Inappropriate management measures will not lead to any further improvements to water pollution. Conversely, if we take suitable control measures, they will significantly improve the water quality status.

\subsection{Water pollution control strategies round the country and abroad}

\subsubsection{Strategies for water pollution control abroad}

Many lakes have created serious eutrophication problems after the rapid economic development in foreign countries, so foreign countries started earlier in lake eutrophication control (Wade et al., 2007). As a result, these polluted lakes all recover well after a long period of using a "pollution first, treatment later" governance model. Foreign countries have accumulated a lot of valuable experience in treatment of lake pollution, and it is very useful for our work in water pollution control especially for those similar types lakes.

Lake Biwa is the largest freshwater lake in Japan, with a total area of $670 \mathrm{~km}^{2}$. It is a major drinking water source of over 1400 people. During the early 1970s, along with the lake area of industrial development and population growth, water pollution in Lake Biwa became evident after a massive outbreak of freshwater red tide in 1977 and subsequent outbreak of blue-green algae in 1983. The Shiga Prefectural Government has set up the target treatment of lake in stages, and managed this lake step by step. Through the enforcement of the target, the prefecture promoted the construction of sewerage facilities, nitrate and phosphorus effluent regulation of factories and commercial facilities, and banned the use of household detergent containing phosphorus. Consequently, the loads of nitrogen and phosphorus have been significantly reduced, and the concentrations of phosphorus and chlorophyll $a$ in the water of Lake Biwa have declined up to the present (Hiroya et al., 2012). The eutrophication phenomenon of Lake Moses in America and Lake Bled in Slovenia after the implementation of pollutant emissions and water dilution engineering has radically improved (Gantzer et al., 2010). Measures in the city park lake in Baton Rouge, Louisiana and Lake Trummen, Sweden (Tu et al., 2007) were conducted mainly by Lake Dredge over the whole lake sediments. In the city park lake, the surface sediment which was contaminated by heavy metals was placed in the depression, and then it was covered by deep uncontaminated sediment. The remaining lake sediments were used to construct beach in the south part in order to increase the storage capacity of the lake of oxygen and reduce the frequent death of fish (Ruley and Rusch, 2002).

Lake improvement is a long-term formidable task, we should not be anxious for success; conversely, we must respect the laws of nature, from the perspective of harmonious coexistence of people and lakes, thereby, restore the ecological environment of the lake (Dong et al., 2011).

\subsubsection{Strategies for water pollution control in Dianchi Lake}

\section{Issues related to the management of Dianchi Lake "Zero O'clock Action"}

Dianchi Lake is included in the national "three rivers and three lakes" pollution control project outlined in the "Ninth Five-Year Plan” (1996-2000). Meanwhile, Yunnan Province and Kunming City have taken a series of measures to improve water conditions in Dianchi Lake. Particularly due to the implementation of Zero o'clock Action, industrial pollution has been effectively controlled.

In 1999 the "standard emission directive to industry" was issued. It instructed companies around the Dianchi watershed to treat their discharged wastewater appropriately by zero o'clock on 1 May 1999 to meet the state wastewater emission standard. If any company did not meet the standard by the deadline, it would be required to stop operations or it would be closed. This was called Zero O'clock Action (Q. G. Wang et al., 2006; Y. Wang et al., 2006). The industrial pollution control effect was remarkable and was particularly evident around Dianchi Lake, where 249 major enterprises completed the task. The total amount of industrial pollution into the lake was thus reduced from $10-30 \%$ to $2-14 \%$ (He et al., 2011).

However, some problems still remain. Many factories made some temporary changes to meet the mission standards set by the government. Once the region was no longer being scrutinized, these companies returned to their prior polluting methods. In addition, many factories were not examined or punished due to a lack of monitoring capacity. 


\section{Regulations for the protection of Dianchi Lake in the Yunnan Province}

Given the environmental deterioration and the demand for clean water, the "Regulations for Protection of Dianchi Lake in Yunnan Province" were passed by the Yunnan provincial government, with implementation beginning on the 1 January 2013. The main features of these regulations include the following:

- The Yunnan Provincial government and the government at all levels will incorporate the protection work of Dianchi Lake into the national economy and social development planning, meanwhile establishing the protection and long-term mechanisms of ecological compensation.

- The Dianchi Lake basin will be divided into three protected areas and an urban drinking water source protection area and will be protected according to the above classifications.

- Reclaiming land from lakes, fish cage aquaculture, and excessive discharge of wastewater and solid waste in the lake will be banned.

- Specific rewards for contributing to the protection of Dianchi Lake will be offered, and legal penalties for activities that violate the regulations will be imposed.

Before the announcement of these regulations, other regulations that protected Dianchi Lake were established by Kunming City in July 1988 . Over the past 24 years, the regulations have played an important role in protecting resources, combating pollution, and improving the ecological environment. However, with the rapid development of the social economy, environmental protection of Dianchi Lake, water ecological balance, and other aspects of water supply and demand have become increasingly prominent. In the wake of so many new problems, provincial, rather than municipal, regulations are needed to resolve these issues. Although the new regulations have met the regulations for improving the lake environment, their long-term efficacy depends on many other factors such as the active collaboration of various sectors of government agencies and enhanced public consciousness about environmental protection.

\section{Lake dredging}

Serious pollutants within the lake have deposited a large amount of silt, which contain various harmful and toxic pollutants that have accumulated over the years. Through the Phase I, II, III projects of lake dredging, $424000 \mathrm{t}$ sediment from Caohai Lake were transferred by dredging, which has significantly improved the water quality of Caohai Lake (Ding and Lai, 2011).

\section{Pollutant interception}

Sewage and garbage are the main sources of pollution in Dianchi Lake. By 2005, eight sewage treatment plants has been built in the Dianchi Lake basin and newly renovated and expanded trunk sewers were approximately 590 kilometers. The sewage collection rate could reach $74 \%$. Meanwhile, the urban garbage removal rate is $95 \%$, and the harmless treatment rate is $93.6 \%$ (Ding and Lai, 2011).

\section{Eutrophication control}

Serious eutrophication was the main problem in Dianchi Lake. In 1999, Kunming City put 240 t of drugs into Caohai Lake, which cost approximately CNY 6 million, to remove algae. Although it had some effect on algal control, there were certain drugs that caused adverse impacts on benthic animals and zooplankton. Therefore, as learned by the practice of Kunming City, using a chemical method to remove algae in a large area of the lake is not suitable. A physical method of removal of the floating algae on the water is another option; however, the energy consumption and product cost are high so it cannot be used at a large scale (He et al., 2012). A third method employs biotechnology. The water hyacinth can curb the spread of algae; however, once the growth of algae is under effective control, the water hyacinth can become a new pollutant. From the above perspectives, the control of algae is still a worldwide problem (Jin et al., 2008; Yan et al., 2012).

\subsubsection{Main problems in the current management strategy}

By comparing the foreign management strategy over strategies for water pollution control in Dianchi Lake, we found that although the environmental management of Dianchi Lake has occurred over several years, and some activities and regulations have been implemented to enhance the lake environment by controlling wastewater emissions and establishing regulations to protect the lakes in the Yunnan Province. However, the effect on the control of lake eutrophication is still unsatisfactory, and there are problems with institutional fragmentation (horizontally and vertically), simple treatment methods, low-intensity investment in pollution control, and a lack of meaningful endogenous pollution control strategies. For example, with lake dredging, the third phase project has already been put into effect. However, despite more than ten years of hard work, only one-tenth of the silt has been cleared out of the lake. Pollutant interception around the lake has been completed, but there are still questions of how to improve efficiency. Considering these kinds of issues and the deficiencies of the available treatment methods, we should analyze the current status of the lake evolution stage and form suitable management strategies for appropriate actions. This 
will provide a basis for ecological restoration planning and policy making in the future.

\subsection{Management strategy for Dianchi Lake}

It has been reported in many studies that Dianchi Lake, which was formed in approximately $3000 \mathrm{ka} \mathrm{BP}$ during the late Pliocene, has entered old-age status in its evolution. Considering its current status, the environmental problems that face Dianchi Lake should be managed differently than those in other lakes, such as Lugu Lake, which is a younger-age lake. As a result, when creating the management strategies for Dianchi Lake, we should consider the function of the lake and protect it through a different classification level.

The "Six Key Programs", including lake interception, ecological restoration, river training, lake dredging, water source protection and water diversion, have made great contributions to water pollution control. Based on the above management strategies and the evolution stage of Dianchi Lake, we should adopt appropriate methods and governing tactics. The water quality in Caohai Lake is below Class V and is now in a heavy eutrophic state. During its long-term evolution, the lake deposited a layer of silt, which is now another source of pollution to the water. Therefore, strengthening endogenous pollution control is the key task for pollution control, and the fundamental improvement of water quality of Caohai Lake depends on the measures taken in the upper reaches of the Caohai Watershed, including further recovery of submerged plants, resource utilization of floating plants and the reinforcement of sediment disposability. As such, the swamping trend and the aging process of Dianchi Lake could be stunted. Waihai Lake is the main water body of Dianchi Lake, and the water quality there is also below Class V and in a moderate eutrophic state. The management strategies for endogenous pollution in Waihai Lake are mainly based on restocking algae-eating fish and the ecological restoration of macrophytes. Only by choosing suitable comprehensive control measures that consider the temporal and spatial changes of water quality can the pollution status of Dianchi Lake be changed.

Beyond that, we should accelerate the development of water transfer projects to carry out water diversion to Dianchi Lake and prevent water shortages in the area. We could thus increase the water circulation rate, shorten the residence time of water, and change the state of Dianchi Lake. Meanwhile, these management strategies could be utilized by other lakes which have same evolution process or types.

\section{Conclusions}

Water conflict between mankind and ecosystem is a key issue for sustainable water resources management. Especially in recent years, due to population growth and economic development, problems of water pollution are getting worse.
So proper management strategies of water conflicts between mankind and ecosystems in these lakes are needed.

The Dianchi basin played a significant role in the social stability and the economic development of the Yunnan Province. This paper has focused on temporal and spatial changes in the water quality and the management strategy for Dianchi Lake. Based on analysis of the water parameters from 2005 to 2012, it was shown that the current status of water quality in Caohai Lake was much worse than that of Waihai Lake, and the water quality in the study area experienced two different periods from 2005 to 2012. Water quality seriously degraded during the economic boom around the period of the Eleventh Five-Year Plan (2005-2010) due to a combination of natural factors and human activities. It then gradually improved from 2010 to 2012 because of the "standard emission directive to industry". Although some activities and regulations were implemented to enhance the lake environment, many problems were still present in the lake management strategy. To solve these problems, it is important that suitable control measures are chosen that account for the temporal and spatial changes of water quality in this old-age lake.

Acknowledgements. This work was supported by the National Major Scientific and Technological Project of China (no. 2012ZX07102-002).

Edited by: Y. Cai

\section{References}

Cai, Y. P., Huang, G. H., Nie, X. H., Li, Y. P., and Tan, Q.: Municipal solid waste management under uncertainty: A mixed interval parameter fuzzy-stochastic robust programming approach, Environ. Eng. Sci., 24, 338-352, 2007.

Cai, Y. P., Huang, G. H., Tan, Q., and Chen, B.: Identification of optimal strategies for improving eco-resilience to floods in ecologically vulnerable regions of a wetland, Ecol. Model., 222, 360369, 2011.

Cai, Y. P., Huang, G. H., Yang, Z. F., and Tan, Q.: Identification of optimal strategies for energy management systems planning under multiple uncertainties, Appl. Energ., 86, 480-495, 2009.

Choudhary, P., Routh, J., and Chakrapani, G. J.: Organic geochemical record of increased productivity in Lake Naukuchiyatal, $\mathrm{Ku}$ maun Himalayas, India, Environ. Earth Sci., 60, 837-843, 2010.

Christofides, A., Efstratiadis, A., Koutsoyiannis, D., Sargentis, G.F., and Hadjibiros, K.: Resolving conflicting objectives in the management of the Plastiras Lake: can we quantify beauty?, Hydrol. Earth Syst. Sci., 9, 507-515, doi:10.5194/hess-9-507-2005, 2005.

Ding, Y. and Lai, J.: The experience and inspiration of Dianchi Lake protection- analysis of urban water environment governance in China, Journal of Southwest University for Nationalities, 32, 111-115, 2011. 
Dong, C., Cai, Y. P., Huang, G. H., and Xu Y.: An interval-parameter minimax regret programming approach for power management systems planning under uncertainty, Appl. Energ., 88, 28352845, 2011.

Du, L. N., Li, Y., Chen, X. Y., and Yang, J. X.: Effect of eutrophication on molluscan community composition in the Lake Dianchi (China, Yunnan), Limnologica, 41, 213-219, 2011.

Gantzer, P. A., Singleto, V. L., and Little, J. C.: Lake and reservoir management. Water Environ. Res., 80, 1743-1790, 2010.

Gao, M. and Yang, H.: Distribution of soil nutrient and its environmental impact under different land utilization in Dounan of Dianchi watershed, J. Anhui Agric. Sci., 34, 6255-6257, 2006.

Gao, L., Yang, H., Zhou, J. M., and Lü, J. J.: Lake sediments from Dianchi Lake: a phosphorus sink or source?, Pedosphere, 14, 483-490, 2004.

Gbolo, P. and Gerla, P.: Statistical analysis to characterize transport of nutrients in groundwater near an abandoned feedlot, Hydrol. Earth Syst. Sci., 17, 4897-4906, doi:10.5194/hess-17-48972013, 2013.

Guo, J. Y., Wu, F. C., Liao, H. Q., Zhao, X. L., Li, W., Wang, J., Wang, L. F., and Giesy, J. P.: Sedimentary record of polycyclic aromatic hydrocarbons and DDTs in Dianchi Lake, an urban lake in Southwest China, Environ. Sci. Pollut. R., 20, 5471-5480, 2013.

Guo, Z. R.: Key task and strategy of pollution control of Dianchi Lake, Yunnan Environ. Sci., 22, 5-8, 2003.

He, J., Chen, J. B., Bai, T., Xiao, D., Li, T. H., and Wu, D. X.: Research on Total Nitrogen Detection Methods in Cyanobacteria from Dianchi Lake, Journal of Yunnan Agricultural University, 27, 882-886, 2012.

He, P., Xiao, W. H., Li, Y. J., Yan, D. H., Zheng, X. D., and Wang, L. N.: Comprehensive Management Mode and Countermeasures of Dianchi Lake Water Pollution in Changing Environment, Water Sci. Eng. Technol., 1, 5-8, 2011.

Hiroya, K., Machiko, N., and Masayoshi, M.: Lake Biwa: Interactions between Nature and People, Springer Netherlands, 2012.

Huan, Y., Wen, H., Cai, J. L., Cai, M. T., and Sun, J. H.: Key aquatic environmental factors affecting ecosystem health of streams in the Dianchi lake watershed, China, Procedia Environmental Sciences, 2, 868-880, 2010.

Jin, X. C., Lu, S. Y., Hu, X. Z., Jiang, X., and Wu, F. C.: Control concept and countermeasures for shallow lakes' eutrophication in China, Frontiers of Environ. Sci. Eng. China, 2, 257-266, 2008.

Kabir, M. A., Dutta, D., and Hironaka, S.: Process-based distributed modeling approach for analysis of sediment dynamics in a river basin, Hydrol. Earth Syst. Sci., 15, 1307-1321, doi:10.5194/hess-15-1307-2011, 2011.

Katsuki, K., Seto, K., Nomura, R., Maekawad, K., and Khima, B.: Effect of human activity on Lake Saroma (Japan) during the past 150 years: Evidence by variation of diatom assemblages, Estuarine, Coast. Shelf Sci., 81, 215-224, 2009.

Laghari, A. N., Vanham, D., and Rauch, W.: The Indus basin in the framework of current and future water resources management, Hydrol. Earth Syst. Sci., 16, 1063-1083, doi:10.5194/hess-161063-2012, 2012.

Lattin, J., Carroll, D., and Green, P.: Analyzing multivariate data, Thomson Learning, New York, 2003.
Le, C., Zha, Y., Li, Y., Sun, D., Lu, H., and Yin, B.: Eutrophication of Lake Waters in China: Cost, Causes, and Control, Environ. Manage., 45, 662-668, 2010.

Li, F. F., Long, L., and Wang, Y. Y.: Measures for Pollution Remedy and Restoration for Water Ecological Environment in Dianchi Lake, J. Anhui Agr. Sci., 40, 15850-15852, 2012.

Liu, W. Z., Li, S. Y., Bu, H. M., and Zhang, Q. F.: Eutrophication in the Yunnan Plateau lakes: the influence of lake morphology, watershed land use, and socioeconomic factors, Environ. Sci. Pollut R., 19, 858-870, 2012.

Lu, P., Mei, K., Zhang, Y. J., Liao, L. L., Long, B. B., Dahlgren, R. A., and Zhang, M. H.: Spatial and temporal variations of nitrogen pollution in Wen-Rui Tang River watershed, Zhejiang, China, Environ. Monit. Assess., 180, 501-520, 2011.

McKenna, J.: An enhanced cluster analysis program with bootstrap significance testing for ecological community analysis, Environ. Modell. Softw., 18, 205-220, 2003.

Ruley, J. E. and Rusch, K. A.: An assessment of long-term postrestoration water quality trends in a shallow, subtropical, urban hyper eutrophic lake, Ecol. Eng., 19, 265-280, 2002.

Shrestha, S. and Kazama, F.: Assessment of surface water quality using multivariate statistical techniques: A case study of the Fuji river basin, Japan, Environ. Model. Softw., 22, 464-475, 2007.

Singh, K. P., Malik, A., Mohan, D., and Sinha, S.: Multivariate statistical techniques for the evaluation of spatial and temporal variations in water quality of Gomti River (India) - A case study, Water Res., 38, 3980-3992, 2004.

State Environment Protection Bureau of China: Methods of monitoring and analysis for water and wastewater, 4th Edn., Environmental Science Press, Beijing, 2002.

Tan, Q., Huang, G. H., and Cai, Y. P.: A Superiority-InferiorityBased Inexact Fuzzy Stochastic Programming Approach for Solid Waste Management Under Uncertainty, Environ. Model. Assess., 15, 381-396, 2010.

Tan, Q., Huang, G. H., Wu, C. Z., Cai, Y. P., and Yan, X. P.: Development of an Inexact Fuzzy Robust Programming Model for Integrated Evacuation Management under Uncertainty, J. Urban Plan. D., 135, 39-49, 2009.

Tanaka, T., Sato, T., Watanabe, K., Wang, Y., Yang, D., Inoue, H., Li, K. Z., and Inamura, T.: Irrigation system and land use effect on surface water quality in river, at lake Dianchi, Yunnan, China, J. Environ. Sci., 25, 1107-1116, 2013.

Tu, J. F., Jiang, X. N., and Zheng, F.: Lake eutrophication management strategy in Europe, Express Water Resour. Hydropower Inform., 28, 8-11, 2007.

Tuo, Y. M.: Eutrophication of Dianchi and its trend and treatment, Yunnan Environ. Sci., 21, 35-38, 2002.

Veld, K. V. and Shogren, J. F.: Environmental federalism and environmental liability, J. Environ. Econom. Manage., 63, 105-119, 2012.

Wade, A. J., Butterfield, D., Griffiths, T., and Whitehead, P. G.: Eutrophication control in river-systems: an application of INCA$\mathrm{P}$ to the River Lugg, Hydrol. Earth Syst. Sci., 11, 584-600, doi:10.5194/hess-11-584-2007, 2007.

Wang, C. M. and Lin, Z. L.: Environmental Policies in China over the Past 10 Years: Progress, Problems and Prospects, Procedia Environ. Sci., 2, 1701-1712, 2010. 
Wang, H. M. and Chen, Y.: Change trend of eutrophication of Dianchi lake and reason analysis in recent 20 years, Yunnan Environ. Sci., 28, 57-60, 2009.

Wang, Q. G., Gu, G., and Higano, Y.: Toward integrated environmental management for challenges in water environmental protection of Lake Taihu Basin in China, Environ. Manage., 37, 579-588, 2006.

Wang, S. M. and Dou, H. S.: The lakes of China, Science Press, Beijing, 1999.

Wang, X. D., Zhang, S. S., Liu, S. L., and Chen, J. W.: A twodimensional numerical model for eutrophication in Baiyangdian Lake, Frontiers of Environ. Sci. Eng., 6, 815-824, 2012.

Wang, Y., Zhang, Z. K., Zhu, D. K., Yang, J. H., Mao, L. J., and Li, S. H.: River-sea interaction and the north Jiangsu plain formation, Quaternary Sci., 26, 301-319, 2006.

Wu, Y. H., Wu, R. J., Xue, B., Qian, J. L., and Xiao, J. Y.: Paleoenvironmental Evolution in Dianchi Lake Area since $13 \mathrm{ka} \mathrm{BP,} \mathrm{J.}$ Lake Sci., 10, 5-9, 1998.

Xia, J., Zhang, Y. Y., Zhan, C. S., and Ye, A. Z.: Water quality management in China: the case of the Huai river basin, Int. J. Water Resour. Develop., 27, 167-180, 2011.

Xing, K. X., Guo, H. C., Sun, Y. F., and Huang, Y. T.: Assessment of the spatial-temporal eutrophic character in the Lake Dianchi, J. Geogr. Sci., 15, 37-43, 2005.

Yan, S. H., Wang, Y., Wang, Z., and Guo, J. Y.: Remediation effects of experimental project using water hyacinth for pollution control in the Lake Caohai, Dianchi, Jiangsu J. Agr. Sci., 28, 10251030, 2012.

Yang, G. S., Ma, R. H., Zhang, L., Jiang, J. H., Yao, S. C., Zhang, M., and Zeng, H. A.: Lake status, major problems and protection strategy in China, J. Lake Sci., 22, 799-810, 2010.
Yang, L. B., Lei, K., Meng, W., Fu, G., and Yan, W. J.: Temporal and spatial changes in nutrients and chlorophyll-a in a shallow lake, Lake Chaohu, China: An 11-year investigation, J. Environ. Sci., 25, 1117-1123, 2013.

Yang, Y. H., Zhou, F., Guo, H. C., Sheng, H., Liu, H., Dao, X., and He, C. J.: Analysis of spatial and temporal water pollution patterns in Lake Dianchi using multivariate statistical methods. Environ. Monit. Assess., 170, 407-416, 2010.

Yu, L. Z., Oldfield, F., Wu, Y. S., Zhang, S. F., and Xiao, J. Y.: Paleoenvironmental implications of magnetic measurements on sediment core from Kunming Basin, Southwest China, J. Paleolimnol., 3, 95-111, 1990.

Yu, Y. J., Guan, J., Ma, Y. W., Yu, S. X., Guo, H. C., and Bao, L. Y.: Aquatic environmental quality variation in Lake Dianchi watershed, Procedia Environ. Sci., 2, 76-81, 2010.

Zan, F. Y., Huo, S. L., Xi, B. D., Zhang, J. T., Liao, H. Q., Wang, Y., and Yeager, K. M.: A 60-year sedimentary record of natural and anthropogenic impacts on Lake Chenghai, China, J. Environ. Sci., 24, 602-609, 2012.

Zhang, Y., Gao, X., Zhong, Z. Y., Chen, J., and Peng, B. Z.: Sediment accumulation of Dianchi Lake determined by 137Cs dating, J. Geogr. Sci., 19, 225-238, 2009.

Zhou, F., Liu, Y., and Guo, H. C.: Application of Multivariate Statistical Methods to Water Quality Assessment of the Watercourses in Northwestern New Territories, Hong Kong, Environ. Monit. Assess., 132, 1-13, 2007. 